\title{
The Inter-relationships between Language, Music and Movement Pattern Learning
}

\author{
By Maria Rosaria D’Acierno*
}

The aim of this paper is to discuss the interrelationships between the learning of a language, the learning of playing a musical instrument and the learning of movement patterns in order to perform physical exercise. Each area of learning is dealt with separately and in a manner that explains in depth the process of learning. An historical account of the importance of language, music and physical exercise is presented with key references to texts from the ancient world and from different cultural backgrounds including the ancient Greeks and early Islamic texts.

\section{Introduction}

Even though verbal communication is one of the main objectives of humankind, the learning of a foreign language has not received much attention. Indeed, Kun (كُ), Fiat, is the command God gave the universe to be, to exist, and then, the world came into existence: (fayakun فيكن). The sound of this single word pronounced by God had the power to give life to a complex nature full of plants and animals, as well as to a more intricate nurture process involving the human being. The association of sound and speech was established from the beginning, thus becoming the very first elements in the universe. Then, among the many battles man had to face in order to survive in a hostile environment, there was the element of standing posture. Following this, music and language gave human beings special features that defined us as humans. In particular, music and language appear in every human society, no matter what other aspects of culture are absent (Nettl, 1954). Consider, for example, the Pirahã, a small tribe from the Brazilian Amazon, whose members speak a language without numbers or concept of counting (Everett, 2005). This language has no fixed terms for colours, no myths are created or narrated, and the Pirahã people do not draw, aside from simple stick figures. Yet they have music in abundance in the form of songs (Patel, 2006).

Musical sounds and language alongside standing posture were the first means used by humans to communicate with one another in order to establish roles within their tribes, but also to thwart the infinite perils within the forests in which they lived. They were, of course, not language, music or movement as are meant nowadays, but the uncertain 'sounds' emitted and the clumsy gestures produced which, after a certain routine, acquired a precise meaning, so as to be able to transfer complete information. At first, they were both rough and imprecise that through practice and repetition and with the structure

"Professor, University of Naples "Parthenope", Italy. 
of the body developing they evolved into more coordinated movements and more sophisticated musical sounds. Words and musical sounds seem to follow a specific rhythm, the rhythm of either a song or a melody or that of rock and pop music; the rhythm and musicality typical of all languages, as well as the rhythm of the movement of our muscles and the rhythm of our heart beats. Music is the art of arranging the sounds of both voices and instruments in a pleasant sequence.

\section{Music, Language and Physical Exercise in the Ancient World}

Music and physical exercise are very ancient skills and have been practised and discussed by the Greeks, Romans, Arabs, in the western as well as in the eastern world. The Greek philosopher, Plato stated that certain musical modes influence the soul in the same manner as some words do. Plato advocated a program of education for young men that incorporated music and

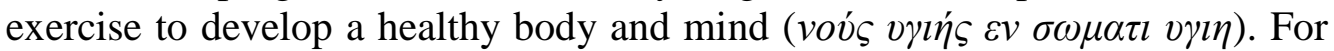
Plato, music ought to be the very first subject to be taught to children, preferably before they were introduced to exercise. Music and exercise, Plato says, must be balanced; too much music makes people effeminate and neurotic and too much exercise makes them uncivilised, violent and ignorant.

According to Aristotle, education should have four parts: reading and writing (grammar), exercise, music and drawing. Of these, music was considered the most important. In his Politics, Aristotle makes a distinction between language, music and exercise by saying that language is useful, music is enjoyable, and exercise is necessary to achieve courage (1338a). In his Republic (378d), Plato, through two of the main characters in the dialogues Socrates and Adeimantus - explains that education in music should be transmitted through speech, in other words through the telling of carefully crafted tales:

Socrates: Shall we begin education with music, and go on to exercise afterwards?

Adeimantus: By all means.

Socrates: And when you speak of music, do you include literature or not?

Adeimantus: I do. Good speech, good harmony, good grace, and good rhythm accompany good disposition.

Socrates believed that a rigorous exercise regime is not desirable, but a good soul produces a good body and a healthy intellect ensures a healthy body (403d-e). Exercise is needed for preventing illness and hence the need for medicine. In short, music and exercise should be used as a prime resource for the development of both a good soul and a well-balanced body. Any excess should be avoided. 
The concept of avoiding excessive exercise is very close to the vision Islamic creed has about both music and physical exercise. In fact as Yusuf alQaradāwi says in his work The Lawful and the Prohibited in Islam, any excess is hâram (forbidden), while the same thing used moderately will be haläl (lawful) (Al-Qaradāwi, 2006). Some sports are halāl (wrestling, archery, spear throwing, horseback riding, hunting), whereas others are häram, depending on whether they are associated with gambling or not. Physical games and exercise are viewed as a source of enjoyment and recreation. Furthermore, physical exercise requires skill and determination, thus creating a proper balance between soul and body preparing people for worship and other obligations.

Music, is considered lawful (halāl) especially if it serves the purpose of curing either the soul or the body (Al-Qaradāwi, 2006). Indeed, Ibn Sīnā, the most famous physician of the Islamic world, known in the western world as Avicenna, points out that music has both physical and psychological effects. Avicenna used music and physical exercise to promote and improve spiritual as well as physiological balance. In his book Canon, he gives detailed information about the association of music with exercise, and exercise with other therapies such as massage, which is equivalent to massaging the muscles before starting to exercise, aromatherapy. He divides exercises into 'strenuous', 'mild', 'vigorous' and 'brisk'. Strenuous exercise includes activities such as wrestling contests, boxing, quick marching, running, jumping over an object higher than one foot, throwing the javelin, fencing, horsemanship, swimming. Mild exercise includes fishing, sailing, being carried on camels, swinging to and fro. Vigorous exercise includes those performed by soldiers in camp, in military sports; field-running, long-jumping, polo, stone-throwing, lifting heavy stones or weights, various forms of wrestling. Brisk exercise involves interchanging places with a partner as swiftly as possible, each jumping to and fro, either in time to music or irregularly (Avicenna, 1999). ${ }^{1}$

Ibn Sinna goes on to assert that the way to achieve good health is through regulation of exercise, food and sleep. He divides an exercise session into three parts: a) massage as preparation for athletics, b) exercise, and c) cold bath to draw impurities towards the surface of the body and assist the physiological dispersion and excretion of poisonous matters/remove fatigue effects. Even the elderly have to do exercise, of course mild exercise, and Ibn Sinnā dedicates an entire chapter of his Canon (from the Greek word $\kappa \alpha v \omega ́ v$, which means law, in Arabic قانون), to advise them about the steps they have to follow:

\footnotetext{
1"Ibn Sina (Avicenna) was known in the West as "the prince of physicians." His synthesis of Islamic medicine, al-Qanun fi'l tibb (The Canon of Medicine), was the final authority on medical matters in Europe for several centuries. Although Ibn Sina made advances in pharmacology and in clinical practice, his greatest contribution was probably in the philosophy of medicine. He created a system of medicine that today we would call holistic and in which physical and psychological factors, drugs, and diet were combined in treating patients"
} 
"For if, towards the end of life, the body is still equable, it will be right to allow exercise. If one part of the body should not be in a first-rate condition, then that part should not be exercised until the others have been exercised.... On the other hand, if the ailment were in the feet, then the exercise should employ the upper limbs: for instance, rowing, throwing weights, lifting weights".

Avicenna (1999) concludes that daily physical practice is more beneficial than medicine for the body, since it helps prevent the accumulation of toxic substances that may cause bacterial infections, diminishes the risk of hectic and prevents plethora. ${ }^{1}$ Exercise renews and revives the innate heat and imparts the necessary lightness to the body" (idem: 378-9). While curing neuropsychiatric conditions such as phobias, melancholia, insomnia, dementia, tremor, epilepsy, etc., and in general, illnesses involving emotions, he associated music, words and physical exercise, each solving a specific function. Thus, while feeling the patient's pulse and reciting aloud to him the names of provinces, districts, towns, streets, and people, he cured his patient (Syed, 2002). He was a composer and a musician, and is also famous for his

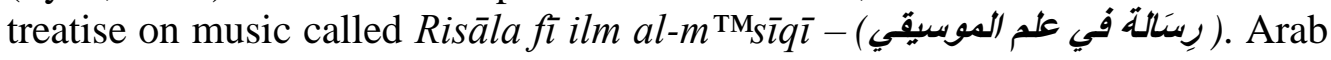
medicine during the Middle Ages was very advanced compared to medieval Europe, and Arab physicians used music not only as a psychological treatment but also to improve and cure the body (Majeed, 2005). Nowadays, the link between music and exercise is gaining wider recognition and is attracting increasing research.

\section{Music, Language and Physical Exercise in the Modern World}

The scientific premise is that language and music are processed independently and by different sides of the brain. There are studies that focus on the differences by basing the dispute mostly on neuropsychological features (e.g. amusia versus aphasia; Lurija et al., 1965; Lochy et al., 2004; Peretz et al., 2005), while others seek common grounds through repetitive rhythmic and melodic sequences or the formation of words and musical tones (Levitin \& Lenon, 2003; Low et al., 2000; Patel, 2008). However, there is evidence that music and language are inextricably linked. Diagram 1 shows the structure of the brain and the different regions that are responsible for music, movement and language learning.

\footnotetext{
${ }^{1}$ Hectic, as for example hectic fever, which regularly recurs every day = a disturbance recurring day after day; plethora $=$ too much blood in the body.
} 
Diagram 1. Motor, Visual, Auditory and Prefrontal Cortex and Cerebellum From: Kraus (2011)

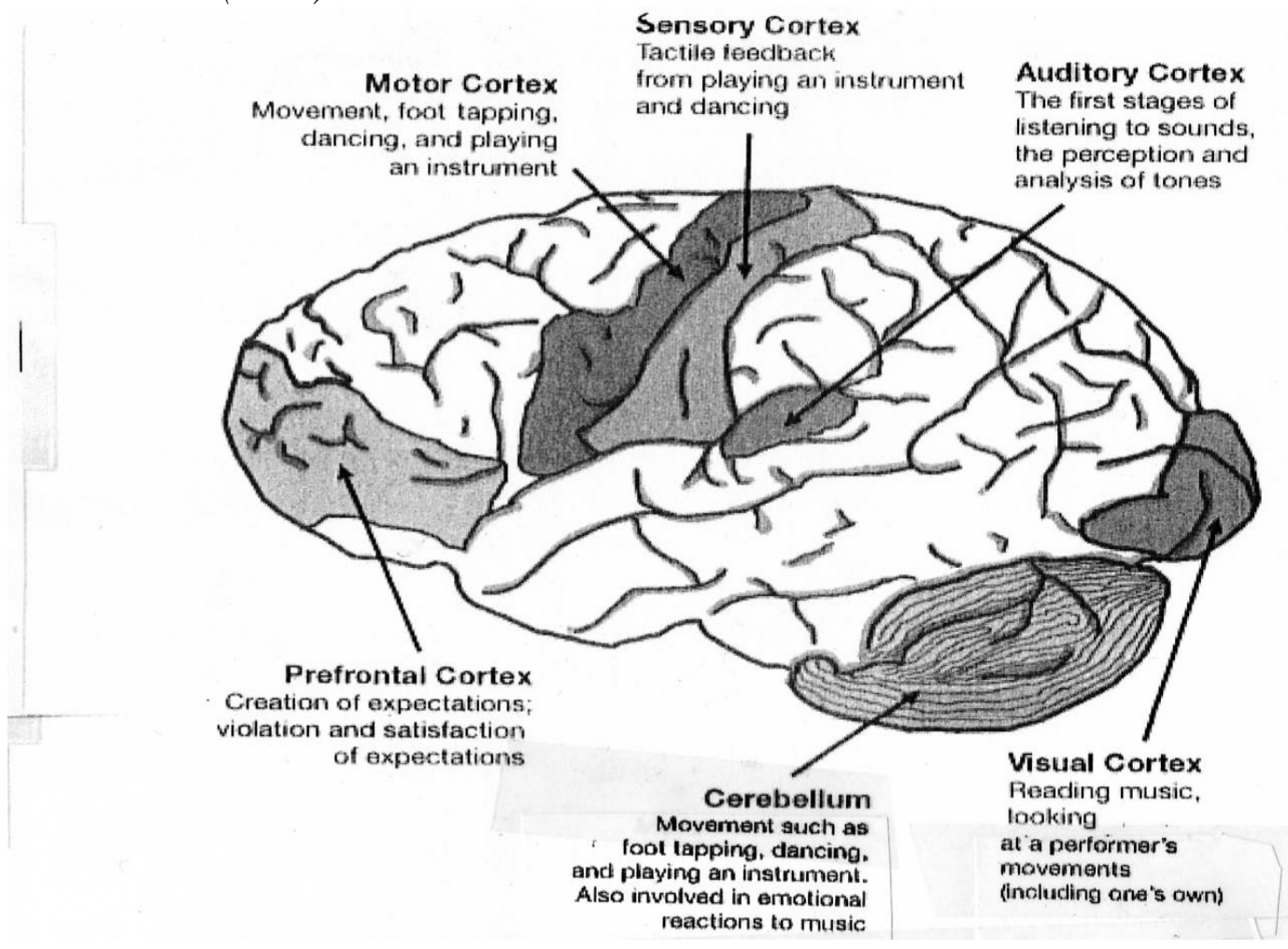

Ullman (2006) discovered similarities between music and language, since they both contain hierarchically organised sequences of basic elements that unfold over time. Music can be broken down into sequences of notes and chords (i.e. three or more notes played simultaneously), whereas language consists of sequences of units such as phonemes, morphemes and words. In both language and music, lower level units are arranged in a rule-governed hierarchical configuration to form higher order structures, such as morphologically complex words, phrases, and sentences in language, and motifs, phrases, and movements in music (Ullman, 2006). He concludes that music and language are governed by the same brain processes; one that is based in the temporal lobe and helps to memorise information (i.e. words and meaning in language and melodies in music), the other, based in the frontal lobe that helps to learn and use the rules governing both language and music, namely rules of syntax and rules of harmony and music perception (Ullman, 2006).

In the past, scientists believed that music only resides in the regions of the right hemisphere of the brain. However, new research has attested that music is scattered in many different sides of the brain, thus providing the brain with greater plasticity making it possible to learn music skills even in adulthood. It was also believed in the past century that there is a 'critical age' (from birth to puberty) for learning a foreign language (Lenneberg, 1967) and hence, the learning of foreign languages was considered an extremely difficult task for adults, as it was thought they had lost ability to train their brain (Roberts, 
1959). However, recent studies have suggested that the only difference between an adult and a child while learning foreign languages is during the acquisition of pronunciation, as the muscles of the vocal tract have not been trained enough for the production of foreign sounds. This skill is so problematic because the muscles have acquired the shape for the emission of sounds belonging to the phonemes and phonology related to the mother tongue (Bruer, 1999).

Conversely, the left hemisphere of the brain, that had been originally considered the only hemisphere assigned to language, receives considerable collaboration from the right side of the brain for many different linguistic as well as musical abilities. Research also indicates that the specialised functions of specific regions of the brain are not fixed at birth but are shaped by experience and learning. A number of studies carried out on animals support this view. These studies reveal the incredible neural flexibility of the developing (and ageing) brain (Rolls \& Baylis, 1986; Xerry et al.1999). Greenenough et al. (1993) showed the synaptic growth in young and ageing rats was raised in complex environments. Karni et al.(1995) demonstrated expansion of cortical involvement in performance of motor tasks following additional learning-in other words, the cortical map can change even in adulthood in response to enriched environmental or learning experiences (Genesee, 2000).

Physical exercise, which was a special prerogative of children and young people, is being increasingly adopted on a broad scale at all ages. It is highly recommended for older people to keep both the body and the brain physically and psychologically active. Moreover, exercise is recommended when it is necessary to repair some external as well as internal dysfunctions of the body as a result of either neurological or behavioural injuries (Rizzolatti \& Gallese, 1997; Wallman \& Sacco, 2007). Movement through physical exercise can both alter and activate plastic changes within the cerebral areas devoted to motor activities. Different parts of the brain often work together to control the body's actions, even though the exact connections have not yet been identified. The connection between different sides of the brain is assured by the so-called 'pons' (bridges in Latin), which are also responsible for maintaining balance, breathing, hearing, taste, bladder control, swallowing, eye movement, and the secretion of saliva and tears. The cerebrum, also called the forebrain and forms the largest section of the brain, is responsible for all cognitive and motor functions, including thought-processing and walking.

It is the cerebellum, however, which mainly regulates and coordinates not only movement but posture, balance and motor learning. Literally, every movement of the body, although planned and executed by the motor cortex of the central nervous system, is regulated and smoothly controlled by the cerebellum (see Diagram 2). The body, in fact, holds its equilibrium from sensory inputs sent from either the eyes or the vestibular system in the ears, or the proprioceptive system (joints, bones, muscles), thus establishing the position of the body in relation to the external environment. For this reason, once the cerebellum receives an injury the consequence is $\operatorname{ataxia}^{8}$ or an 
abnormal gait (Dumurgier et al., 2009). Cerebellar lesions impair the acquisition of a variety of skilled behaviours, and single-unit recording studies have demonstrated dynamic changes in cerebellar activity associated with the acquisition of both conditioned responses and the learning of movement sequences (Cohen \& Kimball, 2004). Below the cerebellum is the brainstem, which connects the spinal cord to the brain. The spinal cord is an integral part of the central nervous system, which carries out sensory as well as motor communication between the body and the brain. The parietal lobe, which belongs to the cortex, also controls movement.

In brief, many different parts of the brain work in unison in order to create the necessary motor operations needed to perform various movements. Thus, parts of the brain collaborate with one another in order to transmit neural signals through the spinal cord with specific movement directions. During these stimuli, new synapses are generated and the brain acquires long-term plasticity, thereby extending the performance of motor activities. Acetylcholine, the chemical neurotransmitter released by neurons at the neuromuscular junction, provokes a series of chemical reactions, which cause the contraction of muscles, a necessary process to enable the execution of complex movements (Wolfson et al., 1990; Pittaccio et al., 2011).

Functional brain imaging studies have reported changes in activation of the cerebellum when subjects acquire a sequence of movements (motor sequence learning) or compensate their movements in response to changes in the mapping of sensorimotor coordinates (motor adaptation). Some investigators have suggested that long-term representations of motor skills are stored within the cerebellum, whereas others have reported findings indicating that a distributed network of motor-related structures outside the cerebellum is sufficient to retain and express well-learned behaviours" (Doyon et al., 2002).

The cerebellum has neural connections with many parts of the body, such that, it continuously receives sensory information from the bones, joints and muscles about their position, rate and direction of movements. To sum up, the striatum, ${ }^{1}$ the cerebellum, and motor cortical regions of the frontal lobe have been thought to be critical for the acquisition and retention of skilled motor behaviours. Motor skills provide a physiological, a psychological and a general cognitive growth, from the moment the newborn child enters the world. Actual, both human growth and developmental processes begin with perceptual motor skills, which are stimulated by sensory information such as visual, auditory and kinaesthetic cues (Kraus, 2011; Hornickel \& Kraus, 2011). By engaging in motor activities, the young child gains confidence in perceiving and controlling its movements. For this reason, it is extremely important to stimulate children to practice jumping, swinging, climbing steps,

\footnotetext{
${ }^{1}$ The striatum is best known for its role in the planning and modulation of movement pathways but is also involved in a variety of other cognitive processes involving executive function. It is a subcortical (i.e., inside, rather than on the outside) part of the forebrain and gets input from the cerebral cortex.
} 
going back and forth on slides and so on. In so doing, they will not only strengthen their muscles and acquire the important perception of balance but, most importantly, they will develop spatial awareness. These activities might be considered spontaneous because nobody tells children how to swing or use a slide; most outdoor games are called 'gross motor activities' and involve the large muscle groups in the body. To this section belong dancing and swimming too, but the difference among them is dependent upon practice as well as on regular training following specific rules.

On the other hand, there are activities involving small muscle groups, which are again divided into spontaneous and learned. The former, for instance grasping an object, throwing a ball or moving the eyes to follow an object, adopt special movements provoked by the visual or auditory stimuli; the latter, called 'fine motor activities', concentrate on learned skills such as the manipulation of buttons, the buckling of shoes, the use of scissors or the assembling of Lego pieces and are guided by precise instructions and consequently follow a precise thought. During our life we use motor skills in a variety of ways, which we have acquired after a well-defined training period, as well as ways which spontaneously occur in consequence of adaptation to our environment. For example, the use of certain muscles recruited to perform a specific task such as swimming or playing a musical instrument or the use of certain muscles called to act in an emergency when we have to re-arrange our body balance in order to avoid a peril. In this latter case, the visual sensors transmit the stimulus to the cerebellum and to other parts of the brain assigned to movement.

Diagram 2. The Cerebellum in and other Parts of the Brain assigned to Music. From: Hornickel \& Kraus (2011).

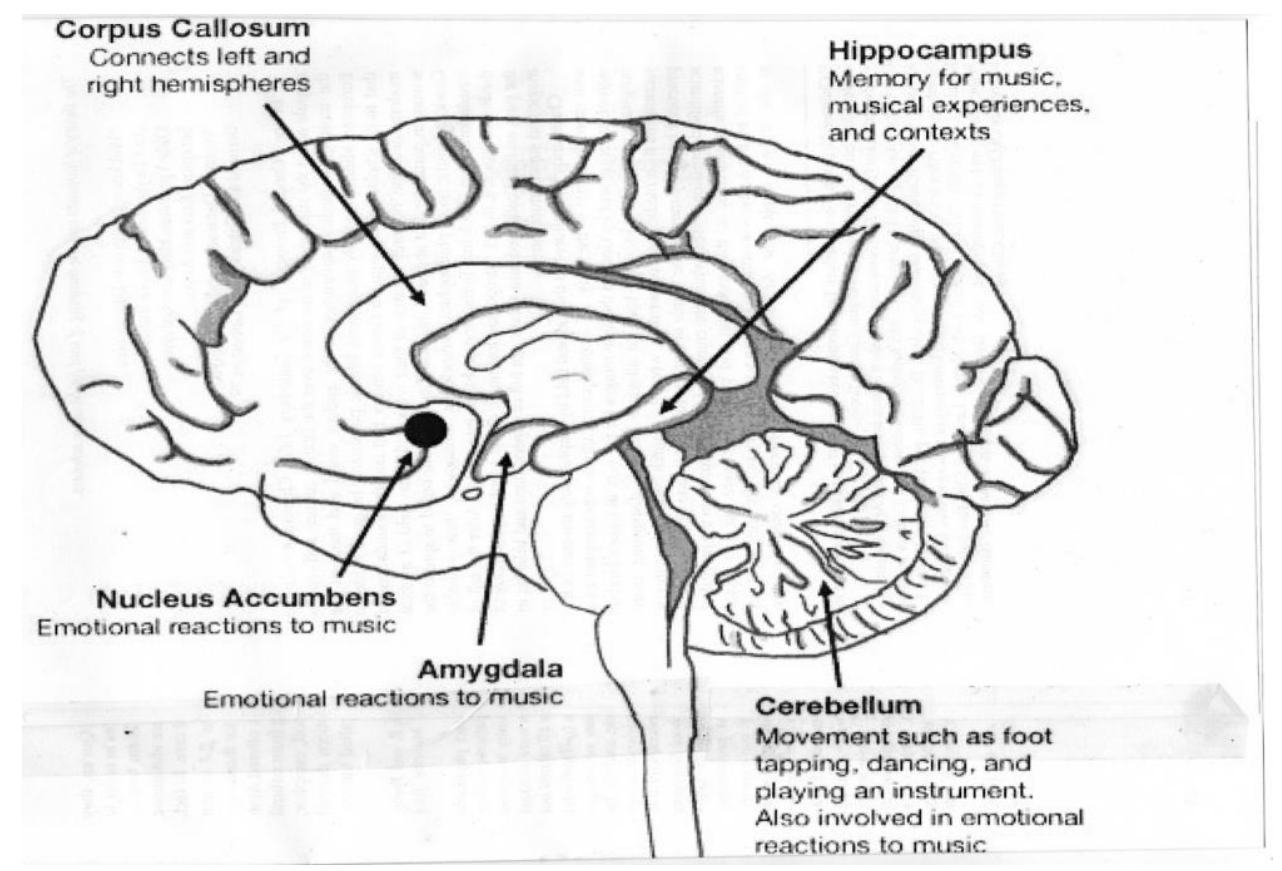


In order to study the dynamic of neural changes occurring in the motor system during the different phases of learning a specific task, Ungerleider et al. (2002) studied sequential finger movements. They found that: (i) the learning of sequential finger movements produces a slowly evolving reorganisation within the primary motor cortex (M1) over the course of weeks and (ii) this change in M1 follows more dynamic, rapid changes in the cerebellum, striatum, and other motor-related cortical areas over the course of days. For some skills, such as learning to play a new melody on a musical instrument, early learning can be facilitated using explicit knowledge (i.e., requiring thought). For most motor skills, however, motor performance is ultimately over learned to a point where it can be performed implicitly (i.e., without thought). As opposed to other forms of memory (e.g., episodic memory), these changes in performance are known to evolve slowly requiring many repetitions over several training sessions (Ungerleider et al., 2002).

Research has postulated that finger movement is of great benefit for three reasons: 1) to establish the changing map of the brain under the influx of input suggesting sequential movements; 2) to maintain flexibility in the movement of fingers, and 3) to reveal the influx on the brain derived from physical exercises when combined with a certain input received by the notes the fingers have to execute in order to create a melody with musical instruments such as the piano, the violin, the lute, the trumpet, the saxophone, the harp, the accordion, etc. Music as well as finger exercises stimulate the brain from different but also from common sides. In so doing, they cause the emergence of new synapses, new energy and longer plasticity.

The effect of music is not only relevant on the physical structure of the brain, but its results are also important from the psychological point of view. In fact, music alters emotional and physiological arousal and can therefore be used prior to competition or training as a stimulant, or as a sedative to calm "up" anxious feelings (Bishop et al., 2007). Music, hence, provides arousal regulation fostering an optimal mindset. Music has been widely recommended as a technique to enhance the psychophysical state of participants in sport and exercise (Terry \& Karageorgis, 1997). The psychophysical (mind and body) effect of music has been investigated in athletic populations, especially in relation to regulating anxiety before competition. Karageorghis et al. (1999) proposed that rhythm response, musicality, cultural impact and association contribute to the motivational qualities of a piece of music. They also identified seven points, that describe the positive effects of music: (a) increased positive mood and reduced negative mood, (b) pre-event activation or relaxation, (c) dissociation from unpleasant feelings such as pain and fatigue, (d) reduced ratings of perceived exertion (RPE) especially during aerobic exercise, (e) extended work output through synchronisation of music with movement, (f) enhanced acquisition of motor skills when rhythm or association is matched with required movement patterns, (g) increased likelihood of athletes achieving flow states and (h) enhanced performance via the above mechanisms (Karageorgis et al., 1999). 
The right type of music can either enhance positive feelings or reduce negative feelings. Fast, upbeat music can induce positive feelings such as excitement and happiness (stimulative effect), whereas slow, soft music can reduce negative feelings such as tension, fatigue and anger (sedative effect). The key characteristics of motivational music are that it has a fast tempo $(>120$ bpm) and a strong rhythm that is energising and it inspires bodily movement (Karageorgis \& Terry, 2011). In aid of selecting the right music, Karageorghis et al. (1999) developed a questionnaire, known as the Brunel Music Rating Inventory (BMRI), which aims at rating the motivational qualities of music. One of the most influential qualities is the so-called 'flow effect' which is an altered state of awareness during physical activity in which the mind and the body function on 'auto-pilot' with minimal conscious effort, an almost trancelike or hypnotic state. Flow has been associated with optimal psychological state and represents complete enjoyment of physical activity. The results revealed a very significant association between ratings of music and ratings of flow. It was concluded that music may have a considerable effect on enjoyment levels during exercise and selecting the 'right' music may be a key factor in maintaining adherence to exercise (Karageorghis et al., 1999).

Priest et al. (2004) highlighted the need to formulate a theory-based method of selecting the appropriate music depending on the athlete and exercise setting to increase motivation. They showed that most of the time practitioners in sport and exercise environments tend to select music in a rather arbitrary manner without considering its motivational characteristics however they did not impose any list of selected tracks, because they proposed that music preferences are a matter of personal choice. Nonetheless, adherence to a few simple guidelines can make it more likely that musical selections applied to individuals or groups will have the desired effect. Scientific research has shown that the application of purposefully selected music can lead to better coordinated movement both during sport and simple physical exercises. To select the right music both coaches and athletes should consider a number of factors such as the type of activity, the effect of that activity on the athlete and the music-playing facilities available. Alongside these considerations, the right volume of music has to be selected so as not to cause discomfort and distraction.

Karageorghis \& Priest (2008) offered examples of motivational music, but emphasised personal preferences in selecting the music. They stated that the use of music during athletic performance may yield long-term benefits such as exercise adherence and heightened sports performance, through a superior quantity and quality of training. Although many athletes today already use music, they often approach its use in a quite haphazard manner. Through applying the principles for using motivational music, athletes and coaches will be able to harness the stimulating, sedative, and work-enhancing effects of music with greater precision (Karageorghis \& Priest, 2008).

Karageorghis \& Terry (2011) divided music into three categories: asynchronous, synchronous and pre-task. Asynchronous music occurs when there is no conscious synchronisation between movement and music tempo. 
Tempo is defined as the most important determinant of response to music and preference for different tempi may be affected by the physiological arousal of the listener and the context in which music is heard. Synchronous music, involves performing repetitive movements in time with its rhythmical elements such as the beat or tempo. Research has consistently demonstrated the efficacy of synchronous music as an ergogenic aid in aerobic activities such as cycle ergometry. Pre-task music can be chosen to have a stimulant or sedative effect before an event. It was shown that participants produced significantly higher scores in a simple motoric task (hand-grip strength test using dynamometry) after listening to stimulating music compared to sedative music. Karageorghis $\&$ Terry (2011) provided a variety of examples of famous athletes who attested to the effects of music during competitions as well as during training. In addition, the effect of only music and music combined with images has been investigated. Theoretically, the supplementation of appropriately chosen music with video footage has the potential to enhance the beneficial effect of such interventions prior to and during sports performance. Video footage of sportspersons demonstrating mastery could manipulate the self-efficacy of an individual as part of a combined music and video intervention. This suggestion has already been supported with the use of personal motivational videos (PMVs) in competitive tennis players following a relatively short intervention period (2 weeks) (Barwood et al., 2009).

Finally, in order to emphasise the link between music and sport, we can consult a list of sports and their related musical tunes: hunting and shooting are associated to classical music (Vivaldi, Strauss, Dunhill); Football to 'Football Fanfara' and 'Football Fever' by Barsotti; cricket to 'Village Rondo' by Matthias von Holst; horse racing to music written by William Alwyn or Robert Farnon, and a lot of general sporting compositions. In other words, every sport has its own songs. However, there is also evidence that for some types of exercise such as cycling and jogging, wearing headphones could result in loss of concentration. For example, a runner wearing headphones may not be able to hear the driver sounding his horn to warn he is manoeuvring into the side road they are about to cross over.

\section{Conclusion}

Music and language are governed by the same brain processes; one that is based in the temporal lobe and helps to memorise information (i.e. words and meaning in language and melodies in music), the other, based in the frontal lobe that helps to learn and use the rules governing both language and music, namely rules of syntax and rules of harmony and music perception (Ullman, 2006). Many different parts of the brain work in unison in order to create the necessary motor operations needed to perform various movements. There is more evidence of the beneficial effects of music than its counterproductive effects, which are restricted to the narrowing of attention related to repetitive 
exercises such as jogging, running and all the sports performed on busy roads or isolated parks. Positive results have been studied from the psychological point of view; in brief, music alters arousal levels, and can therefore be used prior to competition as a stimulant as well as a sedative to relax anxious athletes. In addition, music follows as well as synchronises the movements of the human body. In so doing, music enhances the acquisition of motor skills and creates a better learning environment.

\section{References}

Avicenna (1999). The Canon of Medicine, Great Books of Islamic World. Adapted by Laleh Bakhtiar. Kazi Publications, Chicago: USA.

Barwood, M.J., Weston, N.J.V., Thelwell, R., \& Page, J. (2009). Motivational music and video intervention improves high-intensity exercise performance. Journal of Sport Science and Medicine, vol. 8: 435-442.

Bishop, D.T., Karargeorghis, C.I. \& Loizou, G. (2007). A grounded theory of young tennis palyers'use of music to manipulate emotional state. Journal of Sport \&Exercise Psychology, 29: 584-607.

Bruer, J.T. (1999). The Myth of the First Three Years. The Free Press: A Division of Simon and Schuster Inc.

Cohen, H.S., \& Kimball, K.T. (2004). Decreased ataxia and Improved balance after vestibular rehabilitation. Otolaryngology Head Neck Surgical, 130 (4): 418-425.

Doyon, J., Song, A.W., Karni, A., Lalonde, F., Adams, M.M., \& Ungerleider, L.G. (2002). Experience-dependent changes in cerebellar contribution to motor sequence learning. PNAS, January, 22, Vol. 99 (2): 1017-22.

Dumurgier, J., Elbaz, A., Ducimetiere, P., Tavernier, B., Alpérovitch, A., \& Tzourio, C. (2009). Slow walking speed and cardiovascular death in well functioning older adults: prospective cohort study. British Medical Journal. Nov 10: 339.

Everett, DL. (2005). Cultural constraints on grammar and cognition in Pirahã: Another look at the design features of human language. Current Anthropology, 46: 621-646.

Genesee, F. (2000). Brain research: implications for second language learning. In ERIC Digest, Clearinghouse on Languages and Linguistics, Washington DC: USA.

Greenenough, W.T., Black, J.E., \& Wallace, C.S. (1993). Experience and brain development. In: Johnson, M. (ed.), Brain development and cognition, Blackwell, Oxford, UK. pp. 290-322.

Karageoghis, C.I., Terry, P.C., \& Lane, A.M. (1999). Development and validation of an instrument to assess the motivational qualities of music in exercise and sport: The Brunel Music Rating Inventory. Journal of Sport Sciences, 17: 713-724.

Karageorghis, C.I., \& Priest, L. (2008). Music in sport and exercise: an update on research and application. The Sport Journal, ISSN, 1543-9518: 1-8, United States Sports Academy - America's Sports University.

Karageorghis, C.I., \& Terry, P.C. (2011). Inside Sport Psychology. Human Kinetics, USA.

Karni, A., Meyer, G., Jezzard, P., Adams, M., Turner, R., \& Ungerleider, L. (1995). Functional MRI evidence for adult motor complex plasticity during motor skill learning. Nature, 377: 155-158. 
Kraus N. (2011) Musical training gives edge in auditory processing. Hearing Journal. 64(2):10-16.

Hornickel, J., \& Kraus N. (2011) Objective biological measures for the assessment and management of auditory processing disorder. Current Pediatric Reviews. 7(3): 252-261.

Lenneberg, E.H. (1967). Biological foundations of language. Wiley: New York.

Levitin, D.J., \& Menon, V. (2003). Musical structure is processed in 'language' areas of the brain: a possible role for Brodmann Area 47 in temporal coherence. Neuroimage, 20: 2141-2152.

Lochy, A., Hyde, K.L., Parisel, S., Van Hyfte, S., \& Peretz, I. (2004). Discrimination of speech prosody in congenial amusia. Poster presented at the 2004 meeting of the Cognitive Neuroscience Society, San Francisco, USA.

Low, E.L., Grabe, E., \& Nolan, F. (2000). Quantitative characterisations of speech rhythm: syllable-timing in Singapore English. Language and Speech, 43: 377441.

Lurija, A.R., Tsvetkova, L.S., \& Futer, D.S. (1965). Aphasia in a composer. Journal of the Neurological Sciences, 2: 288-292.

Majeed, A. (2005). How Islam changed medicine. British Medical Journal, 331 (7531): 1486-1487.

Nettl, B. (1954). North American Indian musical styles. Memoirs of the American Folklore Society, Vol. 45, America Folklore Society, Philadelphia: USA.

Patel, A.D. (2008). Music, language, and the brain. Oxford University Press, Oxford: UK.

Peretz, I., Brattico, E., \& Tervaniemi, M. (2005). Abnormal electrical brain responses to pitch in congenial amusia. Annals of Neurology, 58: 478-82.

Plato (360 B.C.). The Republic. Book III. Translated by Benjamin Jowet. Available from: http://classics.mit.edu/Plato/republic.4.iii.html

Roberts, L. (1959). Speech and brain mechanism. Princeton University Press, Princeton, NJ, USA.

Syed, I.B. (2002). Islamic Medicine: 1000 years ahead of its time. Journal of the Islamic Medical Association, 2: 2-9.

Ullman, M. (2006). An introduction to language and linguistics. In: Farold, R., Connor,-Linton, J. (eds.), Language and the Brain. Cambridge University Press: Cambridge, UK.

Ungerleider, L.G., Doyon, J., \& Karni, A. (2002). Imaging brain plasticity during motor skill learning. Neurobiology of Learning and Memory, 78: 553-564.

Terry, P.C., \& Karageorghis, C.I. (1997). Psychological effects of music in sport and exercise: an update on theory, research and application. Journal of Sport Behaviour, 20 (1): 54-68.

Priest, D.L., Karageorghis, C.I., \& Sharp, N.C.C. (2004). The characteristics and effects of motivational music in exercise settings: the possible influence of gender, age, frequency of attendance, and time of attendance. Journal of Sports Medicine and Physical Fitness, 44: 77-86.

Rolls, E.T., \& Baylis, G.C. (1986). Size and contrast have only small effects on the responses to faces neurons in the cortex of the superior temporal sulcus of monkey. Experimental Brain Research, 65: 38-48.

Xerry, X., Merzenich, M., Jenkins, W., \& Santucci, S. (1999). Representational plasticity in cortical area $3 \mathrm{~b}$ paralleling tactual-motor skill acquisition in adult monkey. Cerebral Cortex, 9: 264-276. 
Vol. 2, No. $1 \quad$ D'Acierno: The Inter-relationships between Language, Music...

Rizzolatti, G., \& Gallese, V. (1997). From action to meaning: a neurophysiological perspective. In: Petit, J.L. (ed.), Les Neurosciences et la Philosophe de l'Action, Vrin, Paris, pp. 217-229.

Wallman, K.E., \& Sacco, P. (2007). Sense of effort during a fatiguing exercise protocol in chronic fatigue. Research in Sports Medicine: An International Journal, 15 (1): 47-59.

Wolfson, L., Whipple, R., \& Armeman, P. (1990). Gait assessments in the elderly: a gait abnormality rating scale and its relation to falls. Journal of Gerontology, 45 (1): M12-9. 